\title{
THE IMPACT ON A FOREIGN LANGUAGE CURRICULUM OF FOREIGN LANGUAGE TELEVISION SIGNALS RECEIVED FROM GEOSYNCHRONOUS EARTH SATELLITES
}

\author{
by \\ Victor H. Aulestia
}

\begin{abstract}
The following article describes the acquisition of a geosynchronous earth satellite receiving station and its subsequent impact on the foreign language curriculum at the University of Maryland's Baltimore County campus (UMBC) in Catonsville, MD.
\end{abstract}

KEY WORDS: Prior to 1977, the University of Maryland's Baltimore County campus at Catonsville, MD., offered a traditional foreign language program, which stressed the study of literature. However, around 1977, aided by two major grants from the National Endowment for the Humanities, the Language Department began reshaping its curriculum to place heavy emphasis on the idea of communicative competence. Consequently, a coherent balance was established between the spoken language, literature, and culture studies.

One of the major goals of this new program was to provide students with practical communicative skills along with a cultural awareness required for other fields of study as well as for positions in the public and private sectors involving international contacts. The students would be trained to apply their knowledge of the target language and culture in recurrent, "real life" situations in order to arrive at a thorough understanding of those societies where the language is spoken.

\section{THE INTRODUCTION OF FOREIGN TV PROGRAMS RECEIVED VIA SATELLITE}

In order to transform the language learning experience into a dynamic situation, extensive use of media was made a pre-requisite for the program. To that end, hundreds of audio and video tapes, films, slides, and other materials were made available in the Language Media Center (LMC) for independent use by faculty and students. A state-of-the-art language laboratory was also installed in the LMC. But the final, and most unusual equipment turned out to be the satellite receiving station, located right on top of the building.

The idea of acquiring a satellite receiving station came from various reports which praised the successes of the Rural Satellite Program and the Application Technology Satellite Program in supporting delivery of basic social services along with classroom instruction to isolated areas of developing countries. Based upon these reports, the author conducted additional studies on the feasibility of applying this technology to the learning of foreign language. 
In that subsequent study, the author recommended the purchase of a 3.5 meter parobolic dish antenna, a low noise amplifier, and a professional quality, tuneable video receiver. The lack of on-line experience in dealing with such equipment, along with the obstacles associated with vastly different international video standards, limited the system to receiving programs from US and Canadian satellites.

With four Spanish language channels and three French language channels, there were more than enough video materials available. In addition, there are also useable audio programs in other languages (Polish, Russian, Chinese, etc.)

\section{THE IMPACT OF DAILY VIEWING OF LIVE FOREIGN LANGUAGE TV PROGRAMMING ON FOREIGN LANGUAGE STUDY}

The engineers at the UMBC Television Complex maintain a daily schedule of French and Spanish language commercial and non-commercial television programs from various North American satellites. These signals are de-modulated, amplified, and retransmitted to the Language Media Center and to most classrooms throughout the campus.

Thus, faculty and students may view these programs at any time on the TV monitors mounted in the classrooms. They may be used during class to enhance a lesson, as a warm up for other activities, or even for pure entertainment. Certainly the variety of content, the language usage, cultural characteristics, idiomatic expressions, and even the non-verbal language contained in these programs constitute a unique opportunity to develop listening comprehension as well as enhance cultural awareness.

Based on informal observations and recorded reactions from students, the author offers some tentative assumptions on the effects of this programming. Please note, however, that the following are merely hypotheses which are not supported by scientific study.

\section{Hypotheses on the Use of Foreign Language Television Programs}

1. Oral comprehension of the target language appears to increase proportionally to the amount of time spent viewing the foreign language TV programs.

2. Since the viewing of these programs are, for the most part, purely voluntary, the student motivation to understand the content of the programs seems to be rather high.

3. The attention span of the students is positively affected by the combined use of visual and audio elements.

4. Every television program constitutes a potentially useful tool, not only for the students, but also for those faculty members wishing to sharpen their language skills or remain current on foreign affairs and cultures. 
The positive effect of this programming on the faculty has also come as a pleasant surprise. Many foreign language teachers in the US have had little opportunity to assimilate cultures other than those of their target countries. For instance, many Spanish teachers are trained in the language and cultures of Mexico and Spain. It remains relatively rare to find a teacher whose language exposure includes widespread South American experience. However, the exposure of such teachers to South American cultures via daily television viewing has had a particularly positive effect. Such teachers soon become aware of the sometimes subtle, and other times stark language and cultural differences between countries which ostensibly have the same mother tongue.

\section{CURRENT TECHNOLOGICAL RESTRAINTS}

With the equipment currently in use at UMBC, it is possible to receive only those satellite signals originating between 83 and 143 degrees West. Differing international video standards, receiver limitations, and the size of the parabolic antenna obstruct the reception of numerous potentially interesting satellites. These include the French Symphonie, the Russian Statsioner and Ghorizont satellites, and Intelsat. However, the UMBC instructional media staff designed an improved system which should not only overcome these difficulties, but also feature an uplink or transmitting capability.

In preparing this short article, the author has described the use of satellite technology and associated problems. This research is being done in the spirit of experimentation and has not addressed the political ramifications of operating a private satellite receiving station. Potential users should exercise caution, particularly as regards the licensing requirements of various originating countries. Some nations have, in effect, adopted an "open skies" policy, i.e. satellite signals are the property of the receiving entity, unless the originator actively inhibits unauthorized reception either through legislation or signal scrambling. In some countries, the reception of private communications WITHOUT OFFICIAL PERMISSION is totally illegal. However, as was the case with UMBC, special permission from individual originating stations may be granted for experimental or demonstration purposes.

Victor Aulestia is the Director of the Department of Instructional Media Resources at UMBC. He is an experienced Spanish teacher and was the former Director of the UMBC Language Center. He holds an MAT in Spanish and has completed all coursework towards the Doctorate in Educational Technology.

Victor H. Aulestia, Director

Department of Instructional Media Resources

University of Maryland-Baltimore County

Cantonsville, MD 21228 

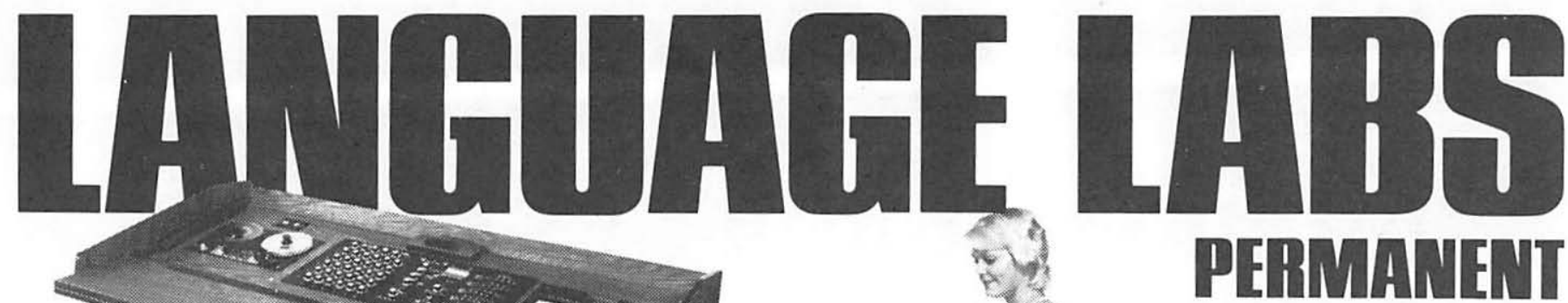

The versatile Audio Classroom 200 is capable of all levels of language teaching. The economical, modular design allows easy expansion to accommodate up to ten program sources.

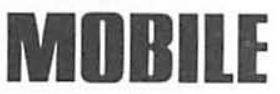

The Mark1A is a complete Levell language lab system self-contained in a mobile cabinet that is easily wheeled from room to room. A budget-saving alternative

Telex Communications, Inc. is a primary manufacturer of educational audio visual products, including Language Labs. Over the years, the on-the-job performance record of these language lab products has earned Telex an enviable reputation for quality and integrity. They are developed and produced in the U.S.A and are sold.

installed and serviced by local factory-

trained and authorized Telex Language Lab dealers.

Write for exciting details

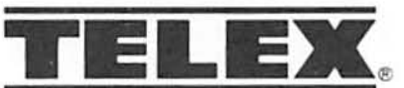

The $\mathrm{C}-150$ offers the lowest possible initial nvestment plus the flexibility to expand into a full, 36-position, Level III system.

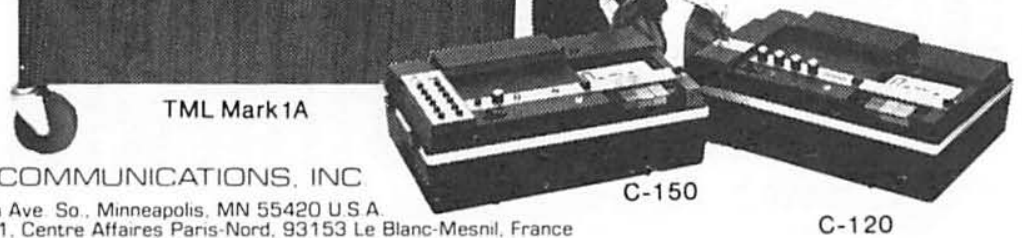

